Article

\title{
Complex Permittivity and Microwave Absorption Properties of OPEFB Fiber-Polycaprolactone Composites Filled with Recycled Hematite $\left(\alpha-\mathrm{Fe}_{2} \mathrm{O}_{3}\right)$ Nanoparticles
}

\author{
Ebenezer Ekow Mensah ${ }^{1}$, Zulkifly Abbas ${ }^{1, *}$, Raba'ah Syahidah Azis 1,2(1), \\ Nor Azowa Ibrahim ${ }^{3}$ id and Ahmad Mamoun Khamis ${ }^{1}$ (D) \\ 1 Department of Physics, Faculty of Science, Universiti Putra Malaysia, 43400 Serdang, Selangor, Malaysia; \\ ebemensek@yahoo.co.uk (E.E.M.); rabaah@upm.edu.my (R.S.A.); akhameis@yahoo.com (A.M.K.) \\ 2 Institute of Advanced Materials, Universiti Putra Malaysia, 43400 UPM Serdang, Selangor, Malaysia \\ 3 Department of Chemistry, Faculty of Science, Universiti Putra Malaysia, 43400 Serdang, Selangor, Malaysia; \\ norazowa@upm.edu.my \\ * Correspondence: za@upm.edu.my; Tel.: +603-8946-6646 or +603-8946-6690
}

Received: 22 March 2019; Accepted: 24 April 2019; Published: 24 May 2019

\begin{abstract}
Recycled hematite $\left(\alpha-\mathrm{Fe}_{2} \mathrm{O}_{3}\right)$ nanoparticles with enhanced complex permittivity properties have been incorporated as a filler in a polycaprolactone (PCL) matrix reinforced with oil palm empty fruit bunch (OPEFB) fiber for microwave absorption applications. The complex permittivity values were improved by reducing the particle sizes to the nano scale via high-energy ball milling for $12 \mathrm{~h}$. A total of 5-20 wt. $\%$ recycled $\alpha-\mathrm{Fe}_{2} \mathrm{O}_{3} / \mathrm{OPEFB} / \mathrm{PCL}$ nanocomposites were examined for their complex permittivity and microwave absorption properties via the open ended coaxial (OEC) technique and the transmission/reflection line measurement using a microstrip connected to a two-port vector network analyzer. The microstructural analysis of the samples included X-ray diffraction (XRD), high-resolution transmission electron microscopy (HRTEM) and Fourier transform infrared spectroscopy (FTIR). At $1 \mathrm{GHz}$, the real $\left(\varepsilon^{\prime}\right)$ and imaginary $\left(\varepsilon^{\prime \prime}\right)$ parts of complex permittivity of recycled $\alpha-\mathrm{Fe}_{2} \mathrm{O}_{3}$ particles, respectively, increased from 7.88 to 12.75 and 0.14 to 0.40 when the particle size was reduced from $1.73 \mu \mathrm{m}$ to $16.2 \mathrm{~nm}$. A minimum reflection loss of $-24.2 \mathrm{~dB}$ was achieved by the $20 \mathrm{wt} . \%$ nanocomposite at $2.4 \mathrm{GHz}$. Recycled $\alpha-\mathrm{Fe}_{2} \mathrm{O}_{3}$ nanoparticles are effective fillers for microwave absorbing polymer-based composites in 1-4 GHz range applications.
\end{abstract}

Keywords: recycled hematite; mill scale; mechanical alloying; complex permittivity; reflection loss

\section{Introduction}

The sharp growth in the electronics industry spanning the microwave frequency range and its associated electromagnetic interference (EMI) problem has led to intensified research into the development of microwave absorbing materials to reduce the impact of EMI. In recent years, ferrite-polymer composites based on spinel or hexagonal ferrites and non-degradable polymer matrices such as epoxy resin [1,2] polyvinylchloride [3] and polyaniline [4,5], have been studied. For an effective microwave absorption, materials having low density, strong mechanical properties, thinness, strong absorption and low-cost are preferred for several applications.

Ferrites have attracted a lot of attention in microwave absorber development in view of their excellent electrical and magnetic properties, and are often synthesized through multi-staged chemical techniques such as sol-gel [6], co-precipitation [1], solid-state [2] and hydrothermal [7] reactions. Among the less extensively used ferrites for microwave absorption applications is hematite $\left(\alpha-\mathrm{Fe}_{2} \mathrm{O}_{3}\right)$, 
a ferrite (corundum-type oxide) which is stable under ambient conditions with unique electrical and magnetic properties. Recently, $\alpha-\mathrm{Fe}_{2} \mathrm{O}_{3}$ was successfully synthesized from industrial mill scale waste material $[8,9]$ through a low-cost technique. Recycled $\alpha-\mathrm{Fe}_{2} \mathrm{O}_{3}$ is cheap, reduces environmental pollution and its generally low dielectric loss properties [10] can be enhanced by reducing the particles to the nanosize for use in polymer composites for microwave absorption applications.

Additionally, the dielectric loss properties of the recycled $\alpha-\mathrm{Fe}_{2} \mathrm{O}_{3} /$ polymer nanocomposites could further be enhanced by reinforcing with carbon bio-based materials for higher microwave absorbing capacities. Carbon bio-based materials from agricultural waste can serve as a low-cost and eco-friendly alternative to the often-used carbon nanotubes (CNT) and graphene. Abdalhadi et al. [11] reported in a recent study that compressed oil palm empty fruit bunch (OPEFB) fiber of $100 \mu \mathrm{m}$ grain size possessed a high loss factor in the 1-4 GHz range. Moreover, OPEFB is an abundant waste material generated by the oil palm industries and the biodegradable fiber has low density, good mechanical and thermal properties. Reinforcing materials with OPEFB fiber could reduce cost, improve dielectric loss properties, enhance thermal stability and improve rigidity. OPEFB fiber and ferrites are easily blended with polymers such as polycaprolactone (PCL), as demonstrated in a study by Ahmad et al. [12].

PCL is a fully biodegradable polymer, easy to blend, lightweight, non-toxic and has good dielectric characteristics. Biodegradable composites reduce the effect on the environment when they are no longer in use since they can be broken down by micro-organisms. By combining a biodegradable polymer with recycled $\alpha-\mathrm{Fe}_{2} \mathrm{O}_{3}$ and carbon bio-based material, a low-cost, light weight magneto-dielectric absorber with increased biodegradability and attractive microwave absorption properties could be fabricated, as reported in a similar work [13].

In this study, $\alpha-\mathrm{Fe}_{2} \mathrm{O}_{3}$ was recycled from mill scale and the particle size reduced to the nanosize through high-energy ball milling in order to enhance the dielectric loss properties. A total of 5-20 wt.\% recycled $\alpha-\mathrm{Fe}_{2} \mathrm{O}_{3}$ nanofiller loadings were incorporated into OPEFB fiber/PCL matrix to fabricate nanocomposites using the melt-blend technique followed by hot molding. The samples were then evaluated for their complex permittivity and microwave reflection loss properties in the $1-4 \mathrm{GHz}$ range.

\section{Materials and Methods}

\subsection{Materials}

The following materials were used for the preparation of the recycled $\alpha-\mathrm{Fe}_{2} \mathrm{O}_{3}$ and the $\alpha-\mathrm{Fe}_{2} \mathrm{O}_{3} / \mathrm{OPEFB} / \mathrm{PCL}$ nanocomposites: Mill scale flakes (Perwaja Sdn. Bhd. Terengganu, Malaysia), Polycaprolactone (Sigma-Aldrich, St. Louis, MO, USA) $97.0 \%$ purity, density $1.146 \mathrm{~g} / \mathrm{cm}^{3}$, Purified OPEFB (Dengkil, Malaysia) ground into $100 \mu \mathrm{m}$ grain size.

\subsection{Synthesis of $\alpha-\mathrm{Fe}_{2} \mathrm{O}_{3}$ Nanoparticles from Mill Scale}

The mill scale flakes were crushed into coarse particles and purified using magnetic and curie separation techniques $[8,9]$. The wustite $(\mathrm{FeO})$ slurry produced was filtered, dried and oxidized at $600{ }^{\circ} \mathrm{C}$ for $6 \mathrm{~h}$ (holding time) in a Protherm furnace to obtain the recycled $\alpha-\mathrm{Fe}_{2} \mathrm{O}_{3}$ which was then milled. The milling was performed at room temperature for $12 \mathrm{~h}$ using SPEX Sample Prep 8000D High-energy Ball Mill (SPEX SamplePrep LLC, Metuchen, NJ, USA) fitted with a $1425 \mathrm{rpm}$ and 50 $\mathrm{Hz}$ motor operating at a clamp speed of 875 cycles/minute and a powder-to-ball ratio of 1:5. For every $50 \mathrm{~min}$ of milling, the steel vials were opened for $2 \mathrm{~min}$ so as to avoid transforming $\alpha-\mathrm{Fe}_{2} \mathrm{O}_{3}$ to $\mathrm{Fe}_{3} \mathrm{O}_{4}[14]$.

\subsection{Fabrication of Recycled $\alpha-\mathrm{Fe}_{2} \mathrm{O}_{3} / \mathrm{OPEFB/PCL}$ Nanocomposites}

The recycled $\alpha-\mathrm{Fe}_{2} \mathrm{O}_{3} / \mathrm{OPEFB} / \mathrm{PCL}$ nanocomposites were fabricated by mixing $5 \%, 10 \%, 15 \%$ and $20 \%$ mass percentages of recycled $\alpha-\mathrm{Fe}_{2} \mathrm{O}_{3}$ nanoparticles with PCL and OPEFB fiber at a fixed mass ratio of 3:7 through the melt blend technique using Brabender Plastograph twin screw extruder (Model 815651, Brabender GmbH \& Co. KG, Duisburg, Germany) at a temperature of $65^{\circ} \mathrm{C}$. The blended 
nanocomposites were then hot pressed at a pressure of $110 \mathrm{~kg} / \mathrm{cm}^{2}$ into $6 \mathrm{~cm} \times 3.6 \mathrm{~cm} \times 0.70 \mathrm{~cm}$ pellets for characterization. The synthesis process is as depicted in Figure 1.

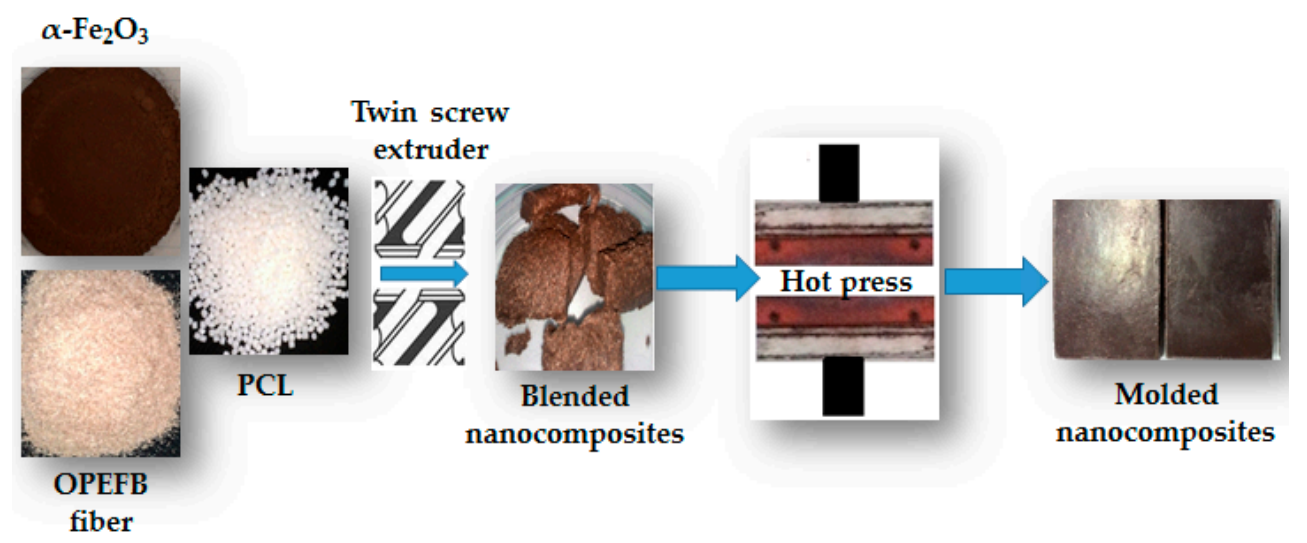

Figure 1. Nanocomposite fabrication. PCL, polycaprolactone.

\subsection{Characterizations}

\subsubsection{Structure and Composition}

The phase composition and structure of the recycled $\alpha-\mathrm{Fe}_{2} \mathrm{O}_{3}$ particles were analyzed using X-ray diffraction (XRD) on a fully automated Philips X-pert system (Model PW3040/60 MPD, Amsterdam, The Netherlands) with $\mathrm{Cu}-\mathrm{K} \alpha$ radiation operating at a voltage of $40.0 \mathrm{kV}$, a current of $40.0 \mathrm{~mA}$ and at a wavelength of $1.5405 \AA$. The diffraction patterns were recorded in the $2 \theta$ range of $10-80^{\circ}$ with scanning speed of $2 \% \mathrm{~min}$. All data were subjected to the Rietveld analysis on PANalytic X'Pert Highscore Plus v3.0 software (PANalytical B.V., Almelo, The Netherlands). The samples were identified by comparing their diffraction peaks with the Inorganic Crystal Structure Database (ICSD).

The size, shape and arrangement of the particles were investigated using the JEM-2100F high resolution transmission electron microscope (HRTEM, JEOL, Tokyo, Japan). The HRTEM images were processed with the ImageJ software (Version 1.50i, NIH, University of Wisconsin, Madison, WI, USA, 2016) to obtain the particle size distribution. The dispersion of recycled $\alpha-\mathrm{Fe}_{2} \mathrm{O}_{3}$ nanoparticles in the PCL/OPEFB matrix was evaluated with JEOL JSM-7600 Field Emission Scanning Electron Microscope (FESEM, JEOL, Tokyo, Japan). The specific surface areas of the $\alpha-\mathrm{Fe}_{2} \mathrm{O}_{3}$ particles were determined by Brunauer-Emmett-Teller (BET) analysis through a Quantachrome Autosorb-1 pore size and surface area analyzer (Quantachrome Instruments, Boynton Beach, FL, USA). Fourier transform infrared spectroscopy (FTIR) analysis of the samples was carried out with the Perkin Elmer Spectrum100 FTIR Spectrometer (PerkinElmer, Inc., Waltham, MA, USA) within the wavelength range of $400-4000 \mathrm{~cm}^{-1}$.

\subsubsection{Complex Permittivity}

The complex permittivity measurements were carried out at room temperature in the $1-4 \mathrm{GHz}$ range using Agilent 85070B open ended coaxial (OEC) dielectric probe connected to the Agilent N5230A PNA-L Network Analyzer (Agilent Technologies, Santa Clara, CA, USA). This technique is appropriate for complex permittivity determination for liquids, semi-solids and solids having flat and smooth surfaces and with a gap-free contact between the probe surface and the materials. A standard one-port, short-air-water calibration was undertaken and a reference standard material (unfilled polytetrafluoroethylene) was characterized to confirm the accuracy of the calibration. The powdered samples were compressed into sample holders to a thickness of $6 \mathrm{~mm}$. Measurements were taken by pressing the probe flat onto the surfaces of the samples while ensuring air-gap free contact throughout the process. The measurement set-up is as illustrated in Figure 2. 


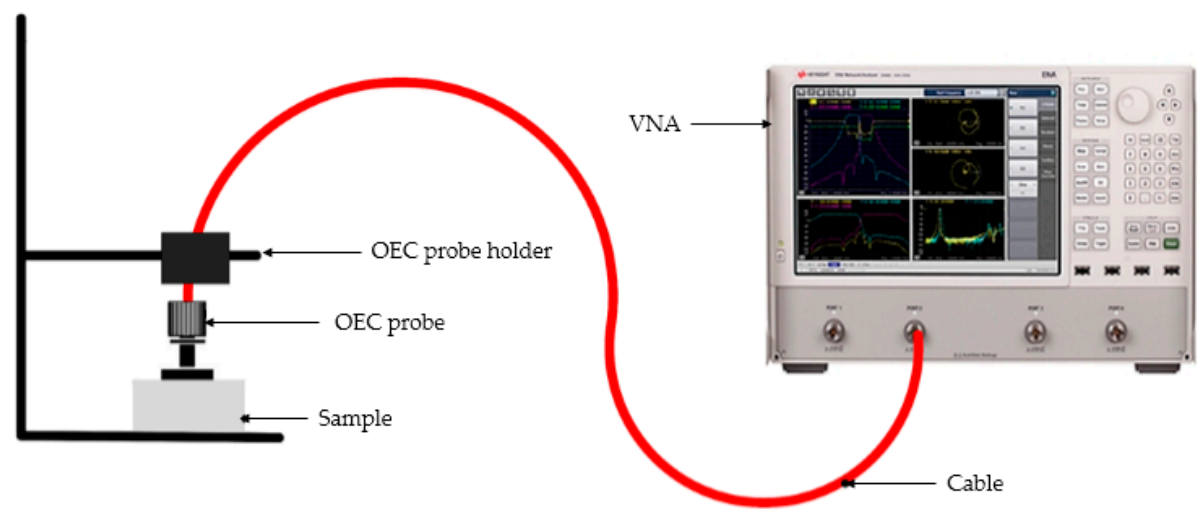

Figure 2. Complex permittivity measurement set-up. OEC, open ended coaxial.

\subsubsection{Microwave Absorption}

The reflection coefficient $\left(\mathrm{S}_{11}\right)$ and transmission coefficient $\left(\mathrm{S}_{21}\right)$ of the nanocomposites were measured using the transmission/reflection line technique based on RT duriod 5880 microstrip (length $=6.0 \mathrm{~cm}$, width $5.0 \mathrm{~cm}$, thickness $0.15 \mathrm{~cm}$ ) connected to a two-port Anritsu MS 2024B VNA Master (Anritsu Corporation, Kanagawa, Japan). A standard calibration (Short, Open and Load) was performed to ensure accuracy of data acquisition. The measurements were carried out by placing the samples flat onto the surface of the microstrip while avoiding any air gap with the strip line. The variation in reflection loss $(\mathrm{dB})$ with frequency in the $1-4 \mathrm{GHz}$ range was then investigated.

\section{Results and Discussion}

\subsection{Structure and Composition}

The XRD patterns of the recycled $\alpha-\mathrm{Fe}_{2} \mathrm{O}_{3}$ particles before and after $12 \mathrm{~h}$ of ball milling are shown in Figure 3. The diffractograms were compared with ICSD standard patterns and all the Bragg peaks of the particles were identified as single phase, with hexagonal (rhombohedral) structure of $\alpha-\mathrm{Fe}_{2} \mathrm{O}_{3}$ belonging to the $\mathrm{R}-3 \mathrm{c}$ space group. These results are consistent with previously reported studies on $\alpha-\mathrm{Fe}_{2} \mathrm{O}_{3}[15,16]$. Moreover, the identicalness in crystal structure between the milled particles (ICSD: 98-009-4106) and the unmilled particles (ICSD: 98-002-2616) essentially suggests that the $\alpha-\mathrm{Fe}_{2} \mathrm{O}_{3}$ did not transform to $\mathrm{Fe}_{3} \mathrm{O}_{4}$ during the high-energy ball milling since no other phases were identified. Additionally, the peaks of the milled particles broadened while the sharpness decreased, possibly due to the reduction in the crystallite sizes [17].

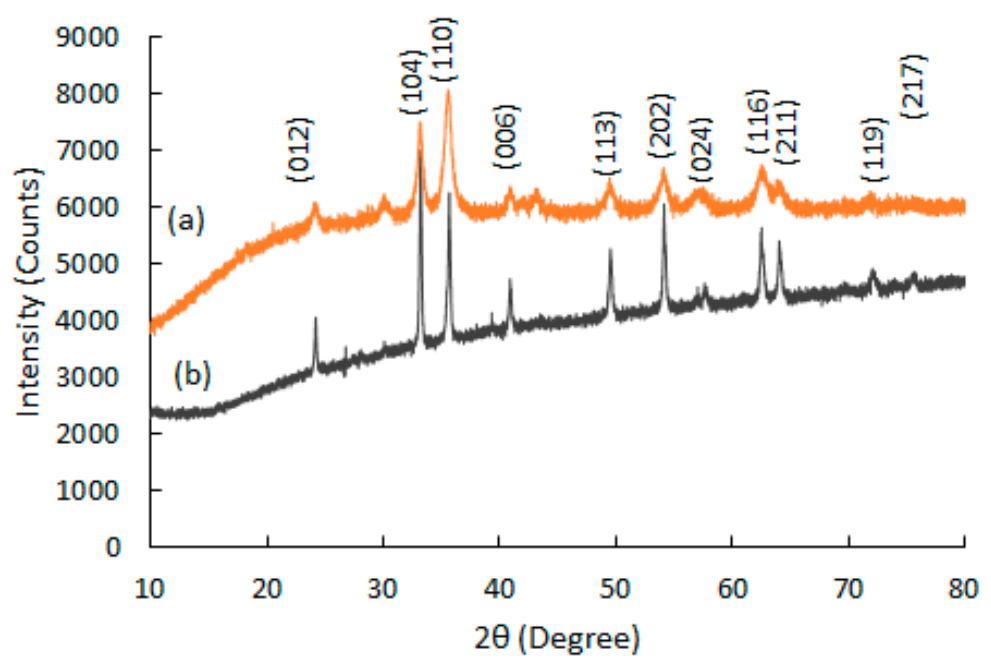

Figure 3. X-ray diffractograms for (a) $\alpha-\mathrm{Fe}_{2} \mathrm{O}_{3}$ milled for $12 \mathrm{~h}\left(R_{\mathrm{wp}}=4.09 \%\right.$, Gof = 9.78); (b) unmilled $\alpha-\mathrm{Fe}_{2} \mathrm{O}_{3}\left(R_{\mathrm{wp}}=2.43 \%\right.$, Gof $\left.=2.27\right)$. 
The average crystallite sizes were estimated from the Scherrer formula given by:

$$
D=\frac{k \lambda}{B \cos \theta}
$$

where $D$ is the crystallite size, $B$ is the Full Width at Half Maximum (FWHM) of the diffraction peaks in radians, $k=0.9, \theta$ is the peak position and $\lambda=1.5405 \AA$. As depicted in Table 1 , the average crystallite sizes of the recycled $\alpha-\mathrm{Fe}_{2} \mathrm{O}_{3}$ particles reduced from 106.2 to $11.1 \mathrm{~nm}$ after $12 \mathrm{~h}$ of high-energy ball milling.

The BET-specific surface area analysis of the particles was examined through the nitrogen adsorption/desorption method and the results are also shown in Table 1. The surface areas of the unmilled and milled particles were, respectively, found to be 0.202 and $13.159 \mathrm{~m}^{2} / \mathrm{g}$, indicating an increase in specific surface area with reduced particle size after milling, which is attributed to the higher bulk density of the nanoparticles due to their decreased volume. The BET-specific surface area is an indication of the exposed surface area per mass unit of the particles and is a function of bulk density and particle size (diameter) as given by the equation [18];

$$
D_{B E T}=\frac{6}{\rho \times S S A}
$$

where $D_{B E T}$ represents the particle size (diameter) and $\rho, S S A$ are the bulk density and specific surface area respectively.

Table 1. Crystallite size, particle size and specific surface area as a function of milling time.

\begin{tabular}{cccc}
\hline$\alpha-\mathrm{Fe}_{2} \mathrm{O}_{3}$ Sample & Crystallite Size $(\mathrm{nm})$ & Particle Size & Specific Surface Area $\left(\mathrm{m}^{2} / \mathbf{g}\right)$ \\
\hline Unmilled & 106.2 & $1.73(\mu \mathrm{m})$ & 0.202 \\
$12 \mathrm{~h}$ milling & 11.1 & $16.2(\mathrm{~nm})$ & 13.159 \\
\hline
\end{tabular}
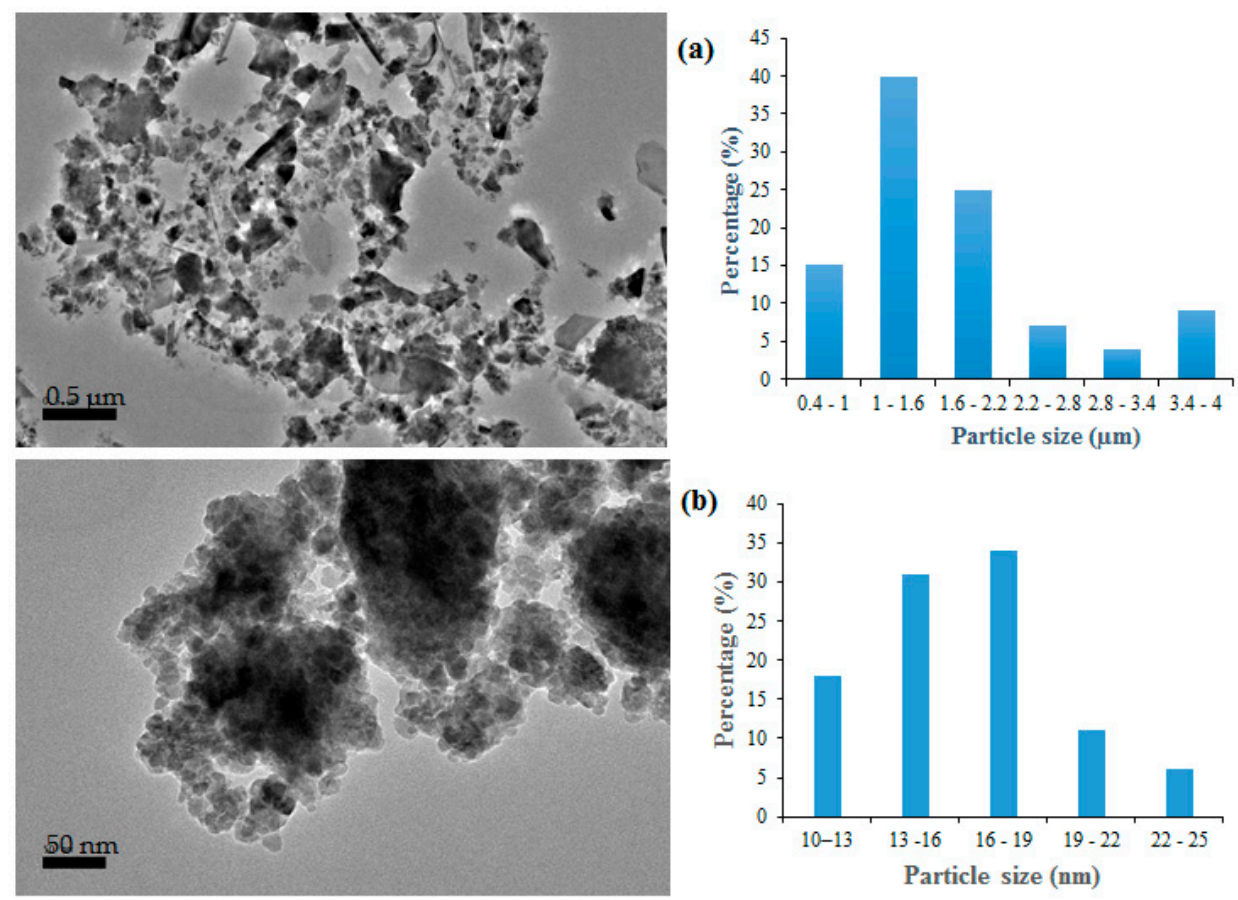

Figure 4. High-resolution transmission electron microscopy (HRTEM) micrographs and particle size distribution of $\alpha-\mathrm{Fe}_{2} \mathrm{O}_{3}$ (a) unmilled (b) nanoparticles. 
HRTEM micrographs and the size distributions of the recycled $\alpha-\mathrm{Fe}_{2} \mathrm{O}_{3}$ particles are illustrated in Figure 4. It can be observed that initially the recycled $\alpha-\mathrm{Fe}_{2} \mathrm{O}_{3}$ particles were loosely formed, randomly shaped and bulky. However, after $12 \mathrm{~h}$ of high-energy ball milling, nanoparticles with distinct aggregation and agglomeration were formed. The agglomeration could be due to higher particle-particle interaction arising from the increased specific surface area [19]. The nanoparticles were largely spherical and the sizes ranged from 10.3 to $24.45 \mathrm{~nm}$ with an average of $16.2 \mathrm{~nm}$, consistent with the estimated crystallite sizes from the XRD analysis. The variations of the particle size with milling time for the recycled $\alpha-\mathrm{Fe}_{2} \mathrm{O}_{3}$ particles are summarized in Table 1.

The surface morphologies of the recycled $\alpha-\mathrm{Fe}_{2} \mathrm{O}_{3} / \mathrm{OPEFB} / \mathrm{PCL}$ nanocomposites are presented in Figure 5. The FESEM micrographs show that there was a uniform dispersal of recycled $\alpha-\mathrm{Fe}_{2} \mathrm{O}_{3}$ nanoparticles which appeared as spherical spots throughout the fractured surfaces. The dispersal increased as the recycled $\alpha-\mathrm{Fe}_{2} \mathrm{O}_{3}$ nanofiller loadings increased in the nanocomposites. The dispersal of recycled $\alpha-\mathrm{Fe}_{2} \mathrm{O}_{3}$ as discrete nanoparticles in the OPEFB-PCL matrix indicates that the nanoparticles were fully embedded in the nanocomposites to form a homogeneous mixture and provided interfacial bonding for the enhancement of the properties of the composites.
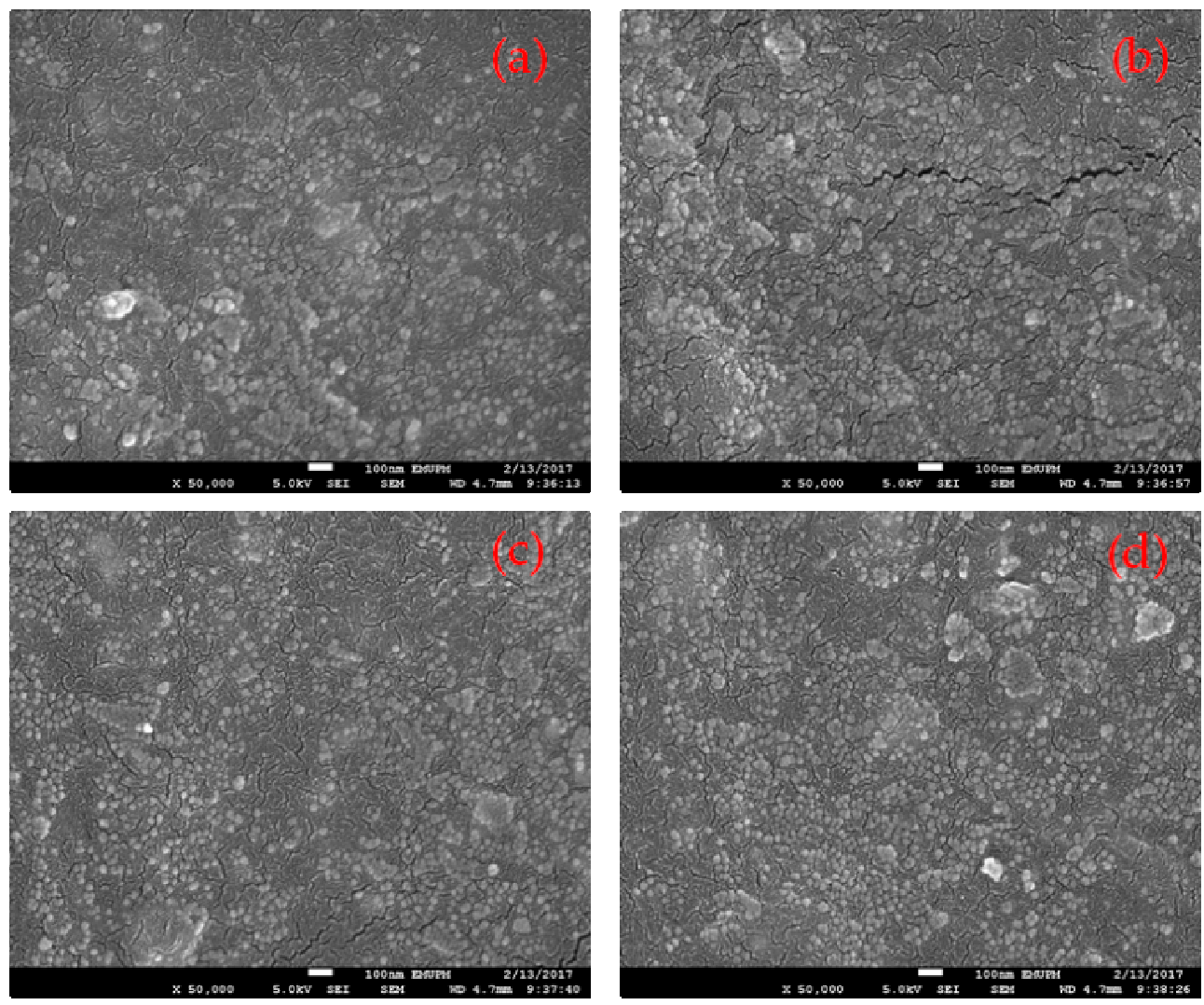

Figure 5. Field Emission Scanning Electron Microscope (FESEM) micrographs of recycled $\alpha$ - $\mathrm{Fe}_{2} \mathrm{O}_{3} / \mathrm{OPEFB} / \mathrm{PCL}$ nanocomposites with (a) $5 \%$ (b) $10 \%$ (c) $15 \%$ (d) $20 \%$ recycled $\alpha$ - $\mathrm{Fe}_{2} \mathrm{O}_{3}$ nanofiller content. OPEFB, Oil palm empty fruit bunch fiber.

FTIR spectroscopy was performed to establish the functional groups present in recycled $\alpha-\mathrm{Fe}_{2} \mathrm{O}_{3}$ nanoparticles, OPEFB fiber and PCL in order to identify the type of the interaction that exists in the nanocomposites. As illustrated in Figure 6, the spectrum for $\alpha-\mathrm{Fe}_{2} \mathrm{O}_{3}$ shows characteristic peaks at 507 and $420 \mathrm{~cm}^{-1}$ which can be ascribed to Fe-O stretching/vibrational modes [20]. The pure PCL spectrum indicates characteristic peaks at 727, 1168, 1366, 1720 and $2940 \mathrm{~cm}^{-1}$ consistent with similar studies $[12,21]$. The spectrum for OPEFB portrays a characteristic absorption band at $3325 \mathrm{~cm}^{-1}$ which could be related to O-H stretching vibration [22]. Characteristic peaks were also found at $1635 \mathrm{~cm}^{-1}$ attributed to absorbed water by cellulose, $2919 \mathrm{~cm}^{-1}$ (C-H stretching vibration) and $1029 \mathrm{~cm}^{-1}$ 
(C-O stretching). It is evident that the spectra for $\alpha-\mathrm{Fe}_{2} \mathrm{O}_{3} / \mathrm{OPEFB} / \mathrm{PCL}$ nanocomposites comprise the characteristic peaks and bands of $\alpha-\mathrm{Fe}_{2} \mathrm{O}_{3}$ nanofiller, PCL polymer and OPEFB fiber. The absence of any significantly new bands or changes in the peak positions in the spectra of the nanocomposites shows that there was no strong interaction between the recycled $\alpha-\mathrm{Fe}_{2} \mathrm{O}_{3}$ nanofiller, PCL polymer and OPEFB fiber. The FTIR results, therefore, suggest that the mixture of recycled $\alpha-\mathrm{Fe}_{2} \mathrm{O}_{3}$ nanoparticles, OPEFB fiber and PCL to form the nanocomposites was physical in nature.

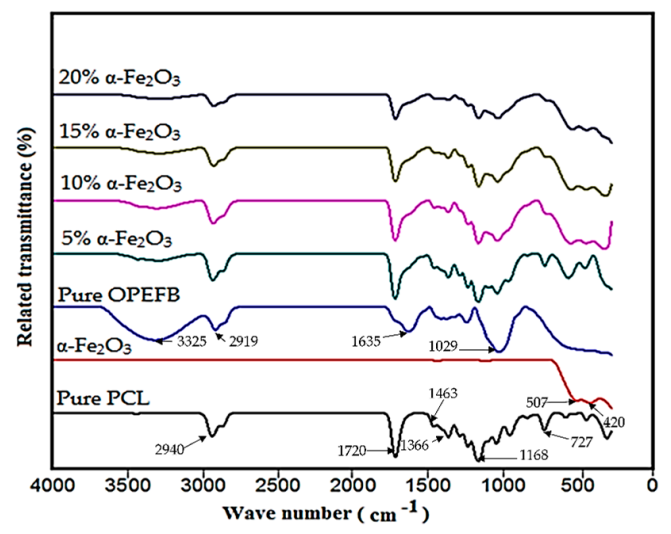

Figure 6. FTIR spectra of pure PCL, recycled $\alpha-\mathrm{Fe}_{2} \mathrm{O}_{3}$, pure OPEFB fiber and $\alpha-\mathrm{Fe}_{2} \mathrm{O}_{3} / \mathrm{OPEFB} / \mathrm{PCL}$ nanocomposites.

\subsection{Complex Permittivity}

In order to investigate the dielectric properties of the recycled $\alpha-\mathrm{Fe}_{2} \mathrm{O}_{3}$ particles, compacted samples were characterized for their real $\left(\varepsilon^{\prime}\right)$ and imaginary $\left(\varepsilon^{\prime \prime}\right)$ parts of the relative complex permittivity $\left(\varepsilon^{*}=\varepsilon^{\prime}-j \varepsilon^{\prime \prime}\right)$. Compacting the samples decreased the void and eliminated air gaps likely to affect the results. The dielectric properties of recycled $\alpha-\mathrm{Fe}_{2} \mathrm{O}_{3}$ particles were examined for reduced particle size dependency, and the variation with frequency is presented in Figure 7. Generally, $\varepsilon^{\prime}$ of the recycled $\alpha-\mathrm{Fe}_{2} \mathrm{O}_{3}$ particles decreased with increase in frequency, a trend common with ferrites and explained based on the Maxwell-Wenger polarization model [23]. The $\varepsilon^{\prime \prime}$ values, however, depicted an increasing profile with frequency, consistent with the OEC calibration profile of water in the studied frequency range. Additionally, both $\varepsilon^{\prime}$ and $\varepsilon^{\prime \prime}$ values showed instabilities in their profiles due to impedance mismatch between the input impedance of the OEC probe and the surface impedance of the compacted samples arising from surface imperfections and voids. The $16.2 \mathrm{~nm}$ recycled $\alpha-\mathrm{Fe}_{2} \mathrm{O}_{3}$ particles had higher $\varepsilon^{\prime}$ and $\varepsilon^{\prime \prime}$ values than the $1.73 \mu \mathrm{m}$ particles throughout the $1-4 \mathrm{GHz}$ range. The $\varepsilon^{\prime}$ of the $16.2 \mathrm{~nm}$ particles varied from 12.75 to 12.03 while the $\varepsilon^{\prime \prime}$ were between 0.40 and 0.54 . For the $1.73 \mu \mathrm{m}$ recycled $\alpha-\mathrm{Fe}_{2} \mathrm{O}_{3}$ particles, the $\varepsilon^{\prime}$ ranged from 7.88 to 7.54 while the $\varepsilon^{\prime \prime}$ values varied between 0.14 and 0.51 . These results demonstrate that the complex permittivity of recycled $\alpha-\mathrm{Fe}_{2} \mathrm{O}_{3}$ particles are significantly enhanced when the particle sizes are reduced to a nanosize.
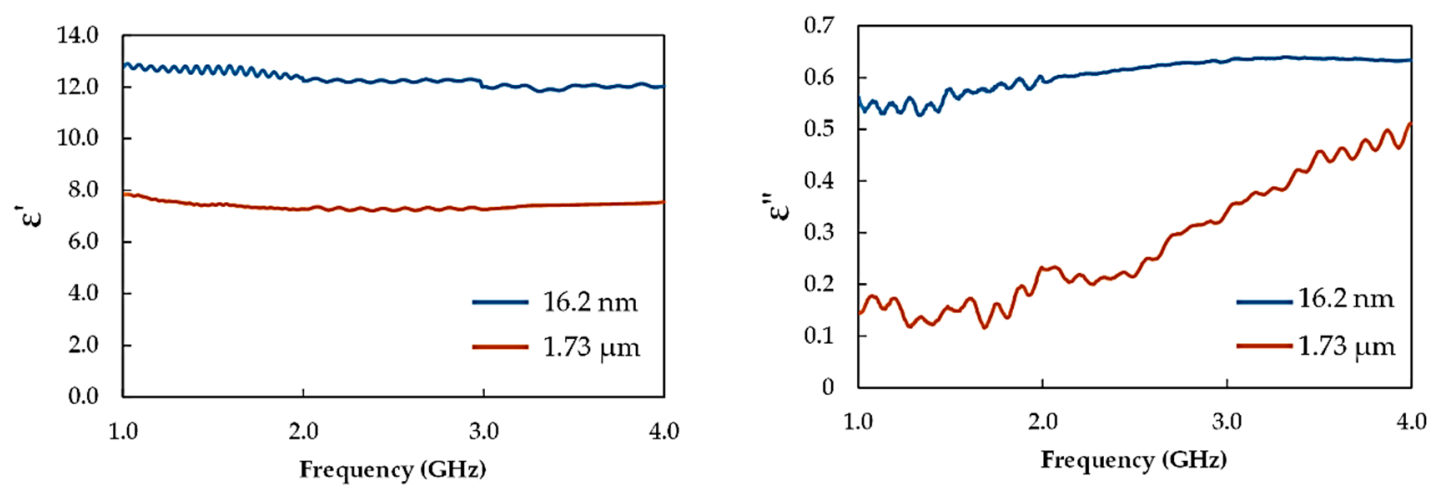

Figure 7. Complex permittivity of recycled $\alpha-\mathrm{Fe}_{2} \mathrm{O}_{3}$ particles. 
The significantly higher permittivity values of the $16.2 \mathrm{~nm}$ recycled $\alpha-\mathrm{Fe}_{2} \mathrm{O}_{3}$ particles can be related to the larger specific surface area and interfacial density resulting in the improvement in interfacial polarization. Additionally, ferrites and other 3-d metal oxide nanoparticles are susceptible to oxygen vacancy formation at the interfacial layers which can greatly influence the magnetic [24] and dielectric [25] properties. Moreover, the compactness of the nanoparticles enabled air-gap-free contact with constituent particles which led to the enhancement of interfacial polarization and therefore complex permittivity.

The effect of the 5-20 wt. $\% 16.2 \mathrm{~nm}$ recycled $\alpha-\mathrm{Fe}_{2} \mathrm{O}_{3}$ nanofiller loadings on the dielectric permittivity of recycled $\alpha-\mathrm{Fe}_{2} \mathrm{O}_{3} / \mathrm{OPEFB} / \mathrm{PCL}$ nanocomposites was investigated, and the variation in $\varepsilon^{\prime}$ and $\varepsilon^{\prime \prime}$ values in the $1-4 \mathrm{GHz}$ range are presented in Figure 8. Clearly, the $\varepsilon^{\prime}$ and $\varepsilon^{\prime \prime}$ of the nanocomposites increased with higher content of the recycled $\alpha-\mathrm{Fe}_{2} \mathrm{O}_{3}$ nanofiller throughout the studied frequency range. Table 2 shows the $\varepsilon^{\prime}$ and $\varepsilon^{\prime \prime}$ values at some specified frequencies and it can be observed that the $\varepsilon^{\prime}$ decreased with frequency while the $\varepsilon^{\prime \prime}$ values increased with frequency for the 5 , 10,15 and $20 \mathrm{wt} . \%$ nanocomposites. As expected, the high complex permittivity values of the recycled $\alpha-\mathrm{Fe}_{2} \mathrm{O}_{3}$ nanofiller and OPEFB fiber contributed to the nanocomposites exhibiting higher permittivity values with increased loadings, in agreement with the results of other inorganic/organic-polymer matrix composites [21]. Complex permittivity properties of a material largely depend on contributions of various forms of polarizations such as interfacial, atomic, orientation and electronic. However, the inclusion of OPEFB fiber in the PCL matrix expectedly enhanced the combined effect of orientation polarization and interfacial polarization [26] as well as the hopping exchange between $\mathrm{O}^{2-}$ and $\mathrm{Fe}^{3+}$ ions at the localized states [26,27] which caused the increase in the permittivity values.
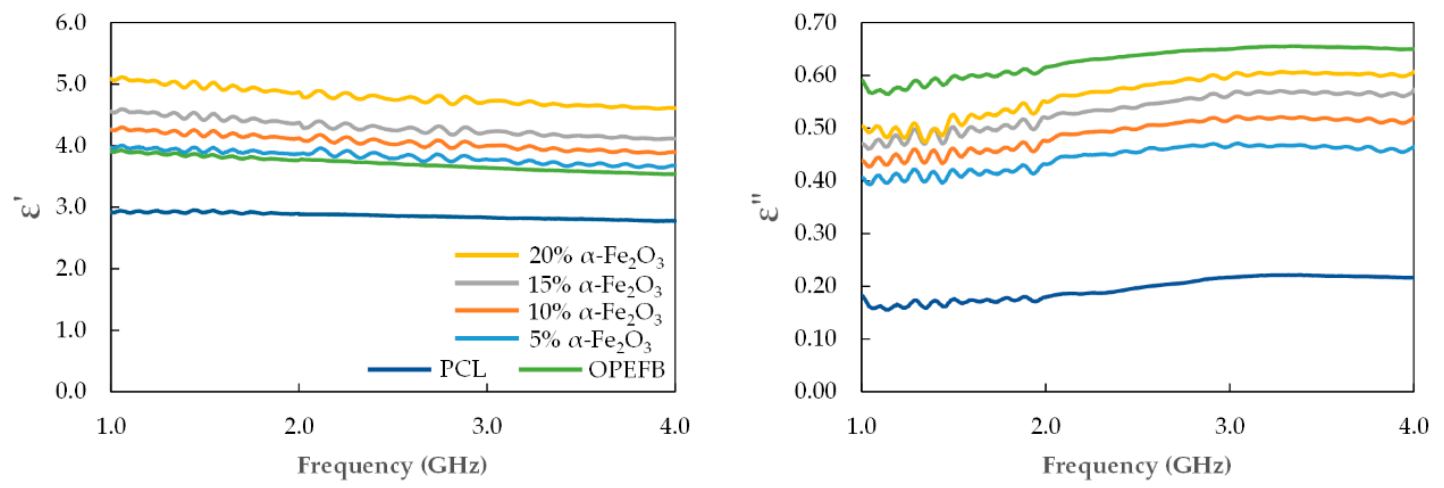

Figure 8. Complex permittivity of recycled $\alpha-\mathrm{Fe}_{2} \mathrm{O}_{3} / \mathrm{OPEFB} / \mathrm{PCL}$ nanocomposites.

Table 2. Variation in $\varepsilon^{\prime}$ and $\varepsilon^{\prime \prime}$ values at specified frequencies.

\begin{tabular}{ccccccc}
\hline \multirow{2}{*}{$\begin{array}{c}\alpha-\mathrm{Fe}_{2} \mathrm{O}_{3} \\
\text { (wt.\%) }\end{array}$} & \multicolumn{2}{c}{$\mathbf{1 ~ G H z}$} & \multicolumn{2}{c}{$\mathbf{2 . 4} \mathbf{G H z}$} & \multicolumn{2}{c}{$\mathbf{4 ~ G H z}$} \\
\cline { 2 - 7 } & $\varepsilon^{\prime}$ & $\varepsilon^{\prime \prime}$ & $\varepsilon^{\prime}$ & $\varepsilon^{\prime \prime}$ & $\varepsilon^{\prime}$ & $\varepsilon^{\prime \prime}$ \\
\hline 5 & 3.97 & 0.40 & 3.88 & 0.45 & 3.67 & 0.46 \\
10 & 4.26 & 0.43 & 4.10 & 0.49 & 3.89 & 0.52 \\
15 & 4.56 & 0.47 & 4.32 & 0.53 & 4.11 & 0.57 \\
20 & 5.08 & 0.50 & 4.82 & 0.57 & 4.60 & 0.60 \\
\hline
\end{tabular}

\subsection{Microwave Absorption}

The microwave absorption properties of the recycled $\alpha-\mathrm{Fe}_{2} \mathrm{O}_{3} / \mathrm{OPEFB} / \mathrm{PCL}$ nanocomposites were deduced from the calculated reflection loss $(R L)$ values using the measured reflection coefficient magnitudes $\left(\left|S_{11}\right|\right)$ obtained via the two-port VNA. The $R L$ values were determined from the expression given by [28];

$$
R L=20 \log \left|S_{11}\right|
$$


The variation of $R L$ with frequency for the nanocomposites are shown in Figure 9. Generally, the 5-20 wt.\% $\alpha-\mathrm{Fe}_{2} \mathrm{O}_{3}$ nanofiller loadings correlated with the decreasing $R L$ values of the nanocomposites throughout the $1-4 \mathrm{GHz}$ range. As indicated in Table 3, the most prominent band was located around $2.4 \mathrm{GHz}$ where the minimum value reached $-24.2 \mathrm{~dB}$ and the maximum -21.5 $\mathrm{dB}$. All the $R L$ values for the nanocomposites were also found to be less than $-10 \mathrm{~dB}$ ( $90 \%$ absorption) with the $20 \mathrm{wt}$.\% nanocomposites obtaining the lowest value. The improvement in the absorption capacity of the nanocomposites could be related to their high dielectric loss properties as a result of the combined effect of enhanced polarization attributed to the recycled $\alpha-\mathrm{Fe}_{2} \mathrm{O}_{3}$ nanofiller and OPEFB fiber. These results demonstrate that the recycled $\alpha-\mathrm{Fe}_{2} \mathrm{O}_{3} / \mathrm{OPEFB} / \mathrm{PCL}$ nanocomposites are capable of significant microwave absorption and would serve as a cheaper and environmentally friendly alternative for applications within the investigated frequency range.

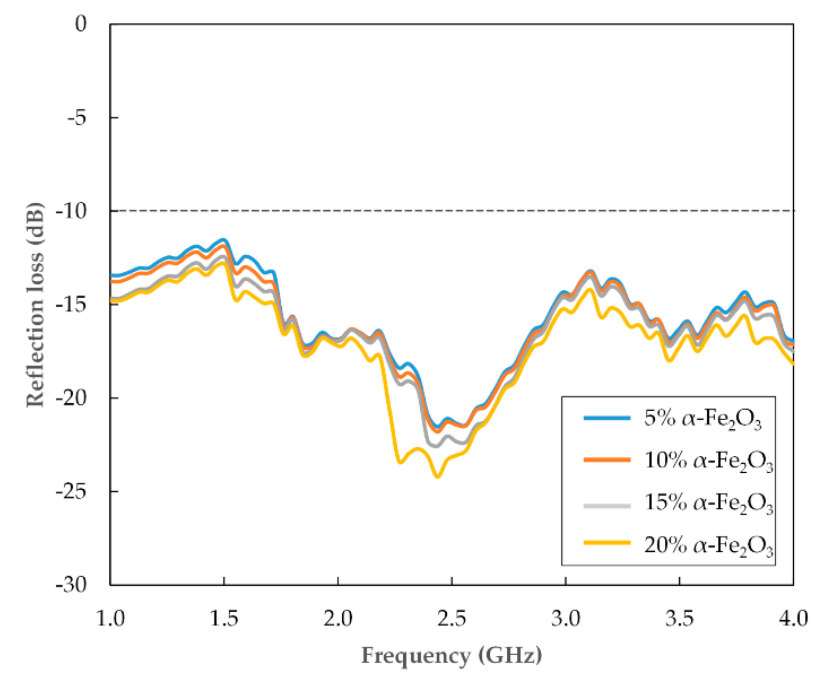

Figure 9. Variation in reflection loss with for the recycled $\alpha-\mathrm{Fe}_{2} \mathrm{O}_{3} / \mathrm{OPEFB} / \mathrm{PCL}$ nanocomposites.

Table 3. Variation in reflection loss (dB) for recycled $\alpha-\mathrm{Fe}_{2} \mathrm{O}_{3} / \mathrm{OPEFB} / \mathrm{PCL}$ nanocomposites.

\begin{tabular}{cccc}
\hline $\boldsymbol{\alpha}-\mathrm{Fe}_{\mathbf{2}} \mathrm{O}_{\mathbf{3}}$ (wt.\%) & $\mathbf{1 ~ G H z}$ & $\mathbf{2 . 4} \mathbf{~ G H z}$ & $\mathbf{4 ~ G H z}$ \\
\hline 5 & -13.4 & -21.5 & -16.9 \\
10 & -13.7 & -21.8 & -17.1 \\
15 & -14.6 & -22.5 & -17.4 \\
20 & -14.7 & -24.2 & -18.1 \\
\hline
\end{tabular}

\section{Conclusions}

$\alpha-\mathrm{Fe}_{2} \mathrm{O}_{3}$ was effectively recycled from mill scale waste material and the complex permittivity improved significantly by reducing the particle size through high-energy ball milling for $12 \mathrm{~h}$. The imaginary part of complex permittivity $\left(\varepsilon^{\prime \prime}\right)$, essential for microwave absorption properties, increased from 0.14 to 0.40 at $1 \mathrm{GHz}$ when the particle size was reduced from 1.73 to $16.2 \mathrm{~nm}$. The 16.2 $\mathrm{nm}$ recycled $\alpha-\mathrm{Fe}_{2} \mathrm{O}_{3}$ nanoparticles were used as filler in PCL matrix reinforced with $100 \mu \mathrm{m}$ OPEFB fiber to fabricate recycled $\alpha-\mathrm{Fe}_{2} \mathrm{O}_{3} / \mathrm{OPEFB} / \mathrm{PCL}$ nanocomposites which showed increased complex permittivity values and good absorption properties with increased nanofiller content. A minimum reflection loss of $-24.2 \mathrm{~dB}$ was obtained for the $20 \mathrm{wt}$ \% nanocomposite at $2.4 \mathrm{GHz}$. The recycled $\alpha-\mathrm{Fe}_{2} \mathrm{O}_{3} / \mathrm{OPEFB} / \mathrm{PCL}$ nanocomposites are cheap, easy to fabricate and are effective for microwave absorption applications in the $1-4 \mathrm{GHz}$ range.

Author Contributions: Conceptualization, Z.A. and N.A.I.; Methodology, E.E.M.; Investigation, E.E.M., and A.M.K.; Writing—original draft preparation, E.E.M.; Resources, R.S.A. and N.A.I.; Formal analysis, Z.A. and E.E.M.

Funding: This research was funded by FRGS Fundamental, grant number 04-01-04-SF0118. 
Acknowledgments: The authors wish to thank the Department of Physics, Faculty of Science, Universiti Putra Malaysia and Institute of Advanced Materials (ITMA), Universiti Putra Malaysia for providing the measurement facilities.

Conflicts of Interest: The authors declare no conflict of interest

\section{References}

1. Rostami, M.; Ara, M.H.M. The dielectric, magnetic and microwave absorption properties of Cu-substituted Mg-Ni spinel ferrite-MWCNT nanocomposites. Ceram. Int. 2019, 45, 7606-7613. [CrossRef]

2. Pratap, V.; Soni, A.K.; Dayal, S.; Abbas, S.M.; Siddiqui, A.M.; Prasad, N.E. Electromagnetic and absorption properties of U-type barium hexaferrite-epoxy composites. J. Magn. Magn. Mater. 2018, 465, 540-545. [CrossRef]

3. Dosoudil, R.; Ušáková, M.; Franek, J.; Grusková, A.; Sláma, J. Dispersion of complex permeability and EM-wave absorbing characteristics of polymer-based composites with dual ferrite filler. J. Magne. Magn. Mater. 2008, 320, e849-e852. [CrossRef]

4. Ali, N.N.; Atassi, Y.; Salloum, A.; Charba, A.; Malki, A.; Jafarian, M. Comparative study of microwave absorption characteristics of (polyaniline/NiZn ferrite) nanocomposites with different ferrite percentages. Mater. Chem. Phys. 2018, 211, 79-87. [CrossRef]

5. Yao, Z.; Lin, H.; Haidry, A.A.; Zhou, J.; Liu, P. Synthesis and high-performance microwave absorption of reduced graphene oxide/Co-doped ZnNi ferrite/polyaniline composites. Mater. Lett. 2019, 236, 456-459.

6. Almessiere, M.A.; Slimani, Y.; El Sayed, H.S.; Baykal, A.; Ercan, I. Microstructural and magnetic investigation of vanadium-substituted Sr- nanohexaferrite. J. Magn. Magn. Mater. 2019, 471, 124-132. [CrossRef]

7. Pawar, R.C.; Um, J.H.; Kang, S.; Yoon, W.-S.; Choe, H.; Lee, C.S. Solvent-polarity-induced hematite $\left(\alpha-\mathrm{Fe}_{2} \mathrm{O}_{3}\right)$ nanostructures for lithium-ion battery and photoelectrochemical applications. Electrochimica Acta 2017, 245, 643-653. [CrossRef]

8. Daud, N.; Azis, R.A.S.; Hashim, M.; Matori, K.A.; Jumiah, H.; Saiden, N.M.; Mariana, N. Preparation and characterization of $\mathrm{Sr}_{1-\mathrm{x}} \mathrm{Nd}_{\mathrm{x}} \mathrm{Fe}_{12} \mathrm{O}_{19}$ derived from steel-waste product via mechanical alloying. Mater. Sci. Forum 2016, 846, 403-409. [CrossRef]

9. Shahrani, M.; Mariana, N.; Azis, R.A.S.; Hashim, M.; Jumiah, H.; Azmi, Z.; Daud, N. Effect of variation sintering temperature on magnetic permeability and grain sizes of $\mathrm{Y}_{3} \mathrm{Fe}_{5} \mathrm{O}_{12}$ via mechanical alloying technique. Mater. Sci. Forum 2016, 846, 395-402. [CrossRef]

10. Yang, H.; Ye, T.; Lin, Y.; Zhu, J.; Wang, F. Microwave absorbing properties of the ferrite composites based on grapheme. J. Alloys Compd. 2016, 683, 567-574. [CrossRef]

11. Abdalhadi, D.M.; Abbas, Z.; Ahmad, A.F.; Ibrahim, N.A. Determining the complex permittivity of oil palm empty fruit bunch fibre material by open-ended coaxial probe technique for microwave applications. BioResources 2017, 12, 3976-3991. [CrossRef]

12. Ahmad, A.; Abbas, Z.; Obaiys, S.; Abdalhadi, D. Improvement of dielectric, magnetic and thermal properties of OPEFB fibre-polycaprolactone composite by adding Ni-Zn ferrite. Polymers 2017, 9, 12. [CrossRef]

13. Yakovenko, O.S.; Matzui, L.Y.; Vovchenko, L.L.; Trukhanov, A.V.; Kazakevich, I.S.; Trukhanov, S.V.; Prylutskyy, Y.I.; Ritter, U. Magnetic anisotropy of the graphite nanoplatelet-epoxy and MWCNT-epoxy composites with aligned barium ferrite filler. J. Mater. Sci. 2017, 52, 5345-5358. [CrossRef]

14. Zdujić, M.; Jovalekić, Č.; Karanović, L.; Mitrić, M. The ball milling induced transformation of $\alpha-\mathrm{Fe}_{2} \mathrm{O}_{3}$ powder in air and oxygen atmosphere. Mater. Sci. Eng. A 1999, 262, 204-213. [CrossRef]

15. Azis, R.S.; Hashim, M.; Saiden, N.M.; Daud, N.; Shahrani, N.M.M. Study the iron environments of the steel waste product and its possible potential applications in ferrites. Adv. Mater. Res. 2015, 1109, 295-299. [CrossRef]

16. Novoselova, L.Y. Hematite nanopowder obtained from waste: Iron-removal sludge. Powder Technol. 2016, 287, 364-372. [CrossRef]

17. Ungár, T. Microstructural parameters from X-ray diffraction peak broadening. Scr. Mater. 2004, 51, 777-781. [CrossRef]

18. Akurati, K.K. Synthesis of $\mathrm{TiO}_{2}$ based Nanoparticles for Photocatalytic Applications; Cuvillier Verlag: Göttingen, Germany, 2008; p. 60. 
19. Kendall, K.; Kendall, M.; Rehfeldt, F. Adhesion of cells, viruses and nanoparticles. Adhes. Cells Viruses Nanoparticles 2011. [CrossRef]

20. Saravanakumar, B.; Jansi Rani, B.; Ravi, G.; Sakunthala, A.; Yuvakkumar, R. Influence of reducing agent concentration on the structure, morphology and ferromagnetic properties of hematite $\left(\alpha-\mathrm{Fe}_{2} \mathrm{O}_{3}\right)$ nanoparticles. J. Mater. Sci. Mater. Electron. 2017, 28, 8093-8100. [CrossRef]

21. Airimioaei, M.; Stanculescu, R.; Preutu, V.; Ciomaga, C.; Horchidan, N.; Tascu, S.; Lutic, D.; Pui, A.; Mitoseriu, L. Effect of particle size and volume fraction of $\mathrm{BaTiO}_{3}$ powders on the functional properties of $\mathrm{BaTiO}_{3} /$ poly (E-caprolactone) composites. Mater. Chem. Phys. 2016, 182, 246-255. [CrossRef]

22. Ibrahim, N.A.; Hashim, N.; Rahman, M.Z.A.; Yunus, W.M.Z.W. Mechanical properties and morphology of oil palm empty fruit bunch-polypropylene composites: effect of adding ENGAGE ${ }^{\mathrm{TM}}$ 7467. J. Thermoplast. Compos. Mater. 2011, 24, 713-732. [CrossRef]

23. Maleknejad, Z.; Gheisari, K.; Raouf, A.H. Structure, microstructure, magnetic, electromagnetic, and dielectric properties of nanostructured $\mathrm{Mn}-\mathrm{Zn}$ ferrite synthesized by microwave-induced urea-nitrate process. J. Supercond. Nov. Magn. 2016, 29, 2523-2534. [CrossRef]

24. Gözüak, F.; Köseoğlu, Y.; Baykal, A.; Kavas, H. Synthesis and characterization of $\mathrm{Co}_{x} \mathrm{Zn}_{1-\mathrm{x}} \mathrm{Fe}_{2} \mathrm{O}_{4}$ magnetic nanoparticles via a PEG-assisted route. J. Magn. Magn. Mater. 2009, 321, 2170-2177. [CrossRef]

25. Kumar, E.R.; Kamzin, A.S.; Prakash, T. Effect of particle size on structural, magnetic and dielectric properties of manganese substituted nickel ferrite nanoparticles. J. Magn. Magn. Mater. 2015, 378, 389-396. [CrossRef]

26. Pickering, K.L.; Efendy, M.G.A.; Le, T.M. A review of recent developments in natural fibre composites and their mechanical performance. Compos. Part A Appl. Sci. Manuf. 2016, 83, 98-112. [CrossRef]

27. Yadav, A.; Varshney, D. Structural and dielectric properties of copper-substituted Mg-Zn spinel ferrites. J. Supercond. Nov. Magn. 2017, 30, 1297-1302. [CrossRef]

28. Widanarto, W.; Ardenti, E.; Ghoshal, S.K.; Kurniawan, C.; Effendi, M.; Cahyanto, W.T. Significant reduction of saturation magnetization and microwave-reflection loss in barium-natural ferrite via $\mathrm{Nd}^{3+}$ substitution. J. Magn. Magn. Mater. 2018, 456, 288-291. [CrossRef]

(C) 2019 by the authors. Licensee MDPI, Basel, Switzerland. This article is an open access article distributed under the terms and conditions of the Creative Commons Attribution (CC BY) license (http://creativecommons.org/licenses/by/4.0/). 